\title{
FORMAÇÃO PARA O SUS: UMA ANÁLISE SOBRE AS CONCEPÇÕES E PRÁTICAS PEDAGÓGICAS EM SAÚDE COLETIVA
}

\author{
TRAINING FOR THE UHS: AN ANALYSIS OF THE PEDAGOGICAL CONCEPTIONS AND PRACTICES IN \\ PUBLIC HEALTH
}

\section{FORMACIÓN PARA EL SUS: UN ANÁLISIS SOBRE LAS CONCEPCIONES Y PRÁCTICAS PEDAGÓGICAS EN SALUD COLECTIVA}

\author{
Patrícia Ribeiro Mattar Damiance ${ }^{1}$ \\ Vera Lúcia Pamplona Tonete ${ }^{2}$ \\ Ana Maria Lombardi Daibem ${ }^{3}$ \\ Maria de Lourdes da Silva Marques Ferreira ${ }^{4}$ \\ José Roberto de Magalhães Bastos ${ }^{5}$
}

Resumo o preparo pedagógico do docente da área da saúde, diante das exigências da educação contemporânea e das diretrizes curriculares nacionais, tem relação direta com a formação de profissionais para atender às necessidades do Sistema Único de Saúde. Fundamentado nessa premissa, este estudo buscou analisar perfil de formação, bases da ação e planejamento pedagógico do docente de enfermagem orientador de estágio em Saúde Coletiva de instituições de ensino superior de dois municípios do centro-oeste paulista, à luz das políticas públicas de educação e saúde. Os dados obtidos foram submetidos à análise de conteúdo, modalidade temática. A análise empreendida apontou que a prática pedagógica dos 11 docentes entrevistados sofria influência da cultura institucional da educação superior brasileira. As atividades rotineiras estavam calcadas em conteúdos das ciências biológicas, organizados sob a égide da assistência de enfermagem; na exposição oral e reprodução de técnicas biomédicas; na desarticulação entre teoria e prática e no isolamento do trabalho docente. Concluiu-se que as competências docentes nas dimensões educacionais, organizacionais e relacionais precisam ser ampliadas em direção ao planejamento da ação pedagógica, aproximando-se dos referenciais teóricos e filosóficos do SUS e da educação contemporânea, em busca de uma prática integrada, coletiva, democrática, promotora da saúde e da qualidade de vida.

Palavras-chave educação; ensino; Saúde Coletiva; Sistema Único de Saúde; estágio clínico.
Abstract The pedagogical preparation of educators in the health area, in the face of the demands of contemporary education and of the Brazilian curriculum guidelines, is directly related to the training of professionals to meet the needs of the Unified Health System. Based on this premise, this study investigates the training profile, the bases of the action, and the pedagogical planning of the professor of nursing who is the advisor of the internship in Collective Health at colleges in two mid-western municipalities in the state of São Paulo, Brazil, under the light of the public policies of education and health. The data obtained were submitted to thematic content analysis. The analysis showed that the pedagogical practice of the 11 professors surveyed was influenced by the institutional culture of Brazilian higher education. Routine activities were modeled based on biological science contents, organized under the aegis of nursing care; on oral and reproductive biomedical techniques; on the disarticulation between theory and practice, and on the isolation of teaching. It was concluded that the teaching skills in the educational, organizational, and relational dimensions need to be enhanced towards the planning of pedagogical action, approaching the theoretical and philosophical references of the UHS and contemporary education, seeking an integrated, collective, democratic, and practice promoting health and quality of life.

Keywords Education; teaching; Public Health; Unified Health System; clinical internship. 


\section{Introdução}

Desde o final do século passado, o governo brasileiro vem postulando que o preparo pedagógico do docente da área da saúde tem relação direta com a formação de profissionais com competências técnico-humanísticas para atender às necessidades do Sistema Único de Saúde (SUS), promover a 'desospitalização" e a Vigilância em Saúde (VS), sendo necessária a adoção de "uma ação educativa crítica, autonomizadora, criativa, capaz de referenciar-se na realidade das práticas e nas transformações políticas, tecnológicas e científicas relacionadas à saúde" (Brasil, 1999, p. 9).

O parecer n. 1.133 do Conselho Nacional de Educação/Câmara de Educação Superior (CNE/CES) reforçou a necessidade da articulação entre educação superior e saúde, objetivando a formação geral e específica dos egressos, com ênfase na promoção, prevenção, recuperação e reabilitação da saúde, definindo as diretrizes curriculares nacionais (DCNs) para o curso de graduação na área da saúde e estreitando ainda mais os laços entre o preparo pedagógico do docente e a formação para o SUS (Brasil, 2001). Essa formação tornou-se explícita com a Constituição Federal de 1988, pois a partir dela coube ao SUS, na figura do Ministério da Saúde, ordenar a formação profissional na área (Brasil, 1988).

Nesse cenário, a educação para a área da saúde passou a ser mais debatida, em um movimento dos setores públicos e da academia em prol de mudanças curriculares dos cursos dessa área, culminando em 2009 com as proposições da Política Nacional de Educação Permanente em Saúde (Brasil, 2009a). Tais proposições valorizam a educação permanente como força propulsora da problematização dos processos de trabalho e da consolidação dos princípios e diretrizes do SUS, nas práticas de atenção. Entretanto, pouco avançaram as discussões sobre as práticas pedagógicas dos docentes na formação em saúde, na dimensão do fazer pedagógico e do conhecer profundamente a área em que lecionam (aspectos técnico-científicos e práticos). Um aspecto relaciona-se ao preparo pedagógico que pode não estar comprometido "com o paradigma da Promoção da Saúde (...) com estímulo à reflexão, à crítica, à capacidade de atuar de forma fundamentada e transformadora" (Lobo Neto et al., 2000, p. 53). Outro pressupõe que existem limitações na compreensão da prática pedagógica "como parte de um processo social e de uma prática social maior" (Souza, 2005, p. 2).

Catani e Gallego (2009, p. 82) apontam alguns limites referentes à prática pedagógica que envolve as histórias de formação, “muitas vezes impregnadas por representações inquestionadas acerca da vida escolar, do ensino, das práticas avaliativas e dos lugares sociais e institucionais de professores e alunos", assim como à própria formação que em geral não propicia a assi- 
milação de concepções teóricas rigorosas e a articulação entre os conhecimentos e os processos de aprender.

Autores e o próprio Ministério da Saúde enfatizam que a desatualização de muitos educadores colabora para formar profissionais de saúde desconsiderando os princípios e valores do SUS (Almeida Filho, 2011; Brasil, 2002, 2004, 2005; Ceccim e Bilibio, 2004). Para Campos (2009, p. 21), “os currículos melhoraram em possibilidades de práticas, estágios, mas ainda dependem muito do professor e de suas relações de trabalho e de estágio a ofertar".

Estudar a prática pedagógica do docente da graduação em saúde sob o prisma da prática social, das complexas relações entre saúde e educação e do exercício da docência na perspectiva dialógica é relevante para se buscar resposta à seguinte pergunta que norteou a pesquisa: “Como se configura a prática pedagógica do docente orientador de estágio em Saúde Coletiva (SC) diante das transformações sociopolíticas da sociedade brasileira e da educação, no contexto da formação para o SUS?"

Neste artigo discute-se o perfil de formação, as bases da ação e o planejamento pedagógico do docente de enfermagem orientador de estágio em SC de instituições de ensino superior (IESs) em duas cidades paulistas, à luz das diretrizes curriculares nacionais e das políticas públicas de educação e saúde.

\section{Aspectos metodológicos}

A pesquisa que deu origem a este artigo foi de natureza qualitativa e desenvolveu-se em quatro instituições de ensino superior de dois municípios do centro-oeste paulista (uma pública e três particulares), selecionadas por fazerem parte do contexto acadêmico e de trabalho das pesquisadoras. Os participantes do estudo foram 11 docentes de enfermagem que supervisionavam estágio na área de SC há pelo menos um ano. Os dados foram coletados por meio de entrevistas gravadas individualmente, seguindo um roteiro de questões norteadoras sobre formação/atuação profissional e prática pedagógica. Para garantir o sigilo, os depoimentos foram identificados pela letra $\mathrm{D}$ (docente), seguida por números $(1,2,3 \ldots)$, respeitando a ordem das entrevistas.

Após transcrição na íntegra, os depoimentos foram submetidos ao método da análise de conteúdo na modalidade temática (Bardin, 2010) e distribuídos em quatro categorias: o campo da ação docente; as bases da ação docente; o plano de ação; e a avaliação da ação. Essas categorias são entendidas, neste estudo, como alguns dos elementos necessários ao exercício da prática docente nos campos da saúde e da educação. 
Neste artigo, recortaram-se as categorias bases da ação e plano de ação docente para fundamentar a discussão sobre a prática pedagógica do docente de enfermagem orientador de estágio em SC.

O estudo aqui abordado foi submetido ao Comitê de Ética em Pesquisa da Faculdade de Medicina de Botucatu (São Paulo) e aprovado como pesquisa clínica FMB-PC-104/2011 em 02/05/2011.

\section{Categorias, temas e interpretações}

O Quadro 1 ilustra o perfil de formação e atuação profissional dos participantes da pesquisa, considerando ano de conclusão do curso; instituição de formação; atuação profissional; pós-graduação e tempo de docência em estágio. O Quadro 2 relaciona as categorias selecionadas, os temas e questões do roteiro de entrevista.

Quadro 1

\begin{tabular}{|c|c|c|c|c|c|}
\hline $\begin{array}{l}\text { Ano de conclusão } \\
\text { do curso }\end{array}$ & $\begin{array}{l}\text { Instituição de formação } \\
\text { (ensino) e título }\end{array}$ & Atuação profissional & $\begin{array}{l}\text { Pós-graduação } \\
\text { lato sensu }\end{array}$ & $\begin{array}{l}\text { Pós-graduação } \\
\text { stricto sensu }\end{array}$ & $\begin{array}{l}\text { Tempo de docência } \\
\text { em estágio }\end{array}$ \\
\hline D1 - 1991 & Privado/Bacharelado & Docente & Saúde do Trabalhador & Saúde Coletiva (mestrado) & 2,5 anos \\
\hline D2 - 1980 & $\begin{array}{l}\text { Privado/Bacharelado } \\
\text { e Licenciatura }\end{array}$ & $\begin{array}{l}\text { Serviço público e } \\
\text { docência }\end{array}$ & $\begin{array}{c}\text { Administração Hospitalar e Educação } \\
\text { e Saúde (Profae) }\end{array}$ & Saúde Coletiva (mestrado) & 2 anos \\
\hline D3 - 2003 & Privado/Bacharelado & $\begin{array}{l}\text { Serviço privado e } \\
\text { docência }\end{array}$ & Ginecologia e Obstetrícia & Saúde Coletiva (mestrado) & 4,5 anos \\
\hline D4 - 1978 & $\begin{array}{l}\text { Privado/Bacharelado } \\
\text { e Licenciatura }\end{array}$ & $\begin{array}{l}\text { Serviço público e } \\
\text { docência }\end{array}$ & $\begin{array}{l}\text { Médico-Cirúrgico/Administração de } \\
\text { Serviços de Saúde Pública }\end{array}$ & Saúde Coletiva (mestrado) & 7 anos \\
\hline D5 - 1981 & Privado/Bacharelado & Docente & $\begin{array}{c}\text { Administração Hospitalar e Serviços } \\
\text { de Saúde }\end{array}$ & $\begin{array}{l}\text { Saúde Coletiva (mestrado } \\
\text { e doutorado) }\end{array}$ & 17 anos \\
\hline D6 - 1983 & Privado/Bacharelado & Docente & $\begin{array}{c}\text { Psiquiatria, Gestão em Saúde } \\
\text { e Infectologia }\end{array}$ & Saúde Coletiva (mestrado) & 8 anos \\
\hline D7 - 1994 & Privado/Bacharelado & Docente & $\begin{array}{l}\text { Metodologia do Ensino Superior, } \\
\text { Especialização em Administração dos } \\
\text { Serviços de Saúde, Enfermagem do } \\
\text { Trabalho }\end{array}$ & $\begin{array}{c}\text { Saúde Coletiva (mestrado), } \\
\text { doutorado em Doenças } \\
\text { Tropicais }\end{array}$ & 16 anos \\
\hline
\end{tabular}


Continuação - Quadro 1

\begin{tabular}{|c|c|c|c|c|c|}
\hline \multicolumn{6}{|c|}{ Formação e atuação profissional dos docentes inseridos na pesquisa } \\
\hline $\begin{array}{l}\text { Ano de conclusão } \\
\text { do curso }\end{array}$ & $\begin{array}{c}\text { Instituição de formação } \\
\text { (ensino) e título }\end{array}$ & Atuação profissional & $\begin{array}{l}\text { Pós-graduação } \\
\text { lato sensu }\end{array}$ & $\begin{array}{l}\text { Pós-graduação } \\
\text { stricto sensu }\end{array}$ & $\begin{array}{l}\text { Tempo de docência } \\
\text { em estágio }\end{array}$ \\
\hline D8 - 1985 & Público/Bacharelado & Docente & Enfermagem Obstétrica & $\begin{array}{l}\text { Mestrado e doutorado } \\
\text { em Enfermagem }\end{array}$ & 20 anos \\
\hline D9 - 1985 & $\begin{array}{l}\text { Público/Bacharelado } \\
\text { e Licenciatura }\end{array}$ & Docente & Saúde Coletiva & $\begin{array}{l}\text { Mestrado em Enfermagem } \\
\text { em Saúde Pública e } \\
\text { doutorado em Enfermagem }\end{array}$ & 23 anos \\
\hline D10 - 1985 & $\begin{array}{l}\text { Público/Bacharelado } \\
\text { e Licenciatura }\end{array}$ & Docente & Enfermagem do Trabalho & $\begin{array}{l}\text { Mestrado e doutorado } \\
\text { em Enfermagem }\end{array}$ & 5 anos \\
\hline D11 - 1998 & $\begin{array}{l}\text { Privado/Bacharelado } \\
\text { e Licenciatura }\end{array}$ & Docente & $\begin{array}{c}\text { Especialização em Saúde Pública/PSF; } \\
\text { Educação e Saúde (Profae) }\end{array}$ & Cursando mestrado & 5 anos \\
\hline
\end{tabular}

Fonte: Os autores.

\section{Quadro 2}

Categorias, temas e questões do roteiro de entrevista relacionado à prática pedagógica do docente de enfermagem orientador de estágio em SC

\begin{tabular}{|c|c|c|}
\hline Categorias & Temas & $\begin{array}{l}\text { Questões do roteiro de entrevista relacionado à } \\
\text { prática pedagógica do docente }\end{array}$ \\
\hline As bases da ação docente & $\begin{array}{l}\text { Modelo da história natural da doença (Leavell e Clark, 1976) } \\
\text { e conteúdos das ciências biológicas e da saúde. }\end{array}$ & $\begin{array}{l}\text { Como ocorrem a seleção e a organização dos conteúdos? Comente } \\
\text { o processo. } \\
\text { As ações propostas aos estudantes fundamentam-se em qual modelo de } \\
\text { atenção à saúde? }\end{array}$ \\
\hline O plano de ação & $\begin{array}{l}\text { Seleção de conteúdos das ciências biológicas e da saúde } \\
\qquad \text { e da assistência de enfermagem; } \\
\text { Organização dos conteúdos sob a égide da assistência } \\
\text { de enfermagem; } \\
\text { Exposição oral e reprodução de técnicas biomédicas; } \\
\text { Desarticulação entre teoria e prática; } \\
\text { Isolamento do trabalho docente. }\end{array}$ & $\begin{array}{l}\text { (...) a seleção e a organização dos conteúdos? Comente o processo. } \\
\text { Como você promove a união dos conhecimentos teóricos e práticos da } \\
\text { saúde coletiva na construção da identidade profissional? } \\
\text { Quais atividades são proporcionadas por você que favorecem a integração } \\
\text { entre os princípios e diretrizes do SUS e a prática clínica? } \\
\text { Quais são as suas estratégias educacionais para desenvolver a reflexão } \\
\text { crítica e a atitude contestatória? } \\
\text { Você considera que a instituição ou serviço de saúde em que o estágio é } \\
\text { realizado apoia as suas atividades educativas e envolve-se com a formação } \\
\text { do aluno? }\end{array}$ \\
\hline
\end{tabular}

Fonte: Os autores. 


\section{Formação e atuação profissional dos docentes}

Em relação à formação e à atuação profissional das 11 docentes entrevistadas, oito foram graduadas por instituições de ensino privado entre o final da década de 1970 e o início do século XXI. De fato, as graduações obtidas em IESs privadas têm crescido vertiginosamente no Brasil desde o final do século passado e o começo deste, com um aumento percentual de vagas privadas de 866,9\% entre 1995 e 2003 (Brasil, 2006).

Somente cinco das docentes realizaram curso de licenciatura em enfermagem após a graduação, e todas estavam inseridas em instituições de ensino superior que não ofereciam essa modalidade de curso que visa formar enfermeiros para o exercício da docência em níveis médio e superior da enfermagem (Brasil, 2001). Sabe-se que muitas IESs públicas e privadas ainda não possuem tais cursos.

O artigo 66 da Lei de Diretrizes e Bases da Educação Nacional (LDB) normatiza que "A preparação para o exercício do magistério superior far-se-á em nível de pós-graduação, prioritariamente em programas de mestrado e doutorado" (Meneses et al., 2004, p. 271). Nas universidades e nos centros universitários, de acordo com o artigo 52 da LDB, pelo menos um terço do corpo docente deve possuir titulação acadêmica de mestrado ou doutorado. Contudo, sabe-se que muitos bacharéis que ingressam no ensino superior não têm preparo nem conhecimento pedagógico necessário ao exercício da docência, havendo o predomínio da ideia de que "quem sabe fazer sabe ensinar" (Rosemberg, 2002). Para Pimenta e Anastasiou (2010), as disciplinas que preparam pedagogicamente o aluno no mestrado e no doutorado não têm o peso e a qualidade exigidos para a formação.

Diferentemente das constatações de Rodrigues (2008), nesta pesquisa, em relação à qualificação do corpo docente, somente uma das professoras é especialista; porém, inserida em curso de mestrado. Oito das docentes possuem mestrado na área de SC; e uma, mestrado e doutorado. Assim, o corpo docente está de acordo com o preconizado pela LDB (artigo 66).

Muitas das entrevistadas verbalizaram que não iniciaram a docência na área de SC e que o interesse pela área surgiu após a graduação, pois se graduaram em uma época pré-SUS, quando a amplitude de atuação do enfermeiro na área era bastante restrita. Ao ingressarem em atividades profissionais na década de 1980 e início da de 1990, concomitantemente com as iniciativas de municipalização da saúde, encontraram oportunidades de desenvolvimento pessoal e profissional.

O depoimento a seguir ilustra o exposto e, ao mesmo tempo, indica a falta de preparo para a docência em SC:

Eu fiquei quase vinte anos trabalhando com gestão de hospitais na área privada (...). Pense em um ser que chegou lá e não sabia o que era a lei 8.080! (D5). 
Por sua vez, D9 afirmou seu interesse e sua opção profissional na área ao valorizar a identificação com ela, ainda na graduação. Foi a única docente a prestar esse depoimento:

Eu sempre me identifiquei e tive oportunidade de atuar enquanto enfermeira assistencial e depois na docência. E eu continuei atuando na SC (D9).

Duas profissionais entrevistadas estavam inseridas no SUS desenvolvendo atividades assistenciais e gerenciais; não exerciam a docência exclusivamente. Uma das docentes explicitou a relação entre a sua inserção no SUS e a docência:

Eu utilizo situações que já vivenciei e vivencio ainda. Porque eu acho que é muito bom você estar lá [no serviço] e trazer a teoria. Como estou inserida nesse SUS, e sou uma docente de uma universidade que prepara... então eu trago essa minha prática para dentro da sala de aula, com exemplos. Porque a teoria é teoria. Se você não vir no concreto, muitas vezes é difícil (D2).

O tempo de docência em estágio na área da SC, em Unidade Básica de Saúde (UBS)/Estratégia Saúde da Família (ESF), variou muito entre as participantes: de dois a 23 anos. A ESF foi o campo de ação do estágio curricular em SC. Das 11 entrevistadas, cinco realizavam o estágio exclusivamente em unidades de saúde que seguiam o modelo tradicional de assistência na atenção básica. Portanto, as docentes tinham possibilidade de atuar em um território subsidiadas pelo diagnóstico situacional de determinada área de abrangência, assim como de participar ou executar ações dirigidas aos problemas de saúde da população.

\section{As bases da ação docente}

Em relação ao modelo de atenção à saúde, que fundamenta as ações propostas aos estudantes, as respostas foram diversas, desvelando limitações conceituais. Ressaltaram nos depoimentos os paradigmas biologicista e preventivista, em detrimento da atenção integral à saúde, quando algumas docentes relacionaram modelo de atenção a níveis de atenção. Isso nos remete ao modelo da história natural da doença, de Leavell e Clark (1976), que enfatiza níveis de atenção: primária, secundária e terciária. Nesse modelo, a promoção da saúde (PS) e a proteção específica fazem parte da prevenção primária; o diagnóstico e o tratamento precoce, assim como a limitação da invalidez, na prevenção secundária; e a reabilitação, na prevenção terciária. A PS e a proteção específica são destinadas a promover saúde e bem-estar, 
mas com foco no indivíduo, sem considerar ambiente e estilos de vida (Buss, 2007). As falas ilustram:

Eu trabalho com primário (...) que dentro disso, além de você ter o tratamento, você trabalha muito com a prevenção (D4).

Eu vejo mesmo a atenção primária com eles [alunos] (...) a prevenção primária (D3).

Uma das docentes verbalizou que as ações propostas aos alunos estavam pautadas no modelo de sistematização para a comunidade. Ela se referia ao modelo comunitário, um modelo de gestão das políticas de saúde que vigorou do início de 1970 a meados de 1980, cujo enfoque era preventivista, com ações assistenciais simples e de baixo custo destinadas aos setores mais pobres (Durão, Morosini e Carvalho, 2011). O depoimento enfatiza:

(...) modelo de sistematização para a comunidade (...) então o aluno, ele sabe que ele tem que fazer: sala de espera, ele tem que fazer a consulta de enfermagem (D7).

Ao se retomar o conceito de modelo de atenção à saúde, acrescentando-se o de tecnologia em saúde e linha de cuidado, discutem-se os depoimentos de Dl e D8. As narrativas expressam:

Eu trabalho muito em cima do protocolo municipal de saúde (...) que é o modelo de assistência do município (D1).

(...) é a questão da linha de cuidados, é o que a gente está usando (D8).

Por tecnologia em saúde, entende-se o conjunto de meios (sistemas organizacionais, informacionais, educacionais e de suporte, programas e protocolos assistenciais) e instrumentos (equipamentos, medicamentos, insumos e procedimentos técnicos) por meio dos quais a atenção e o cuidado com a saúde são prestados às populações (Brasil, 2009b). E por linhas de cuidado, o estabelecimento de intervenções em áreas de atenção à saúde com a finalidade de contribuir para adoção de uma prática integral e cuidadora considerando as especificidades dos grupos e as necessidades individuais, sem desconsiderar os modos de viver (Brasil, 2008a).

No Brasil, o modelo de atenção à saúde está relacionado ao conceito de qualidade de vida, aos princípios do SUS e da PS. O informe Lalonde (1974), a Carta de Ottawa (1986) e os movimentos contemporâneos da promoção social da saúde fundamentaram a reorientação do modelo de atenção e a construção de um modelo assistencial voltado à epidemiologia e às ciências 
sociais (Buss, 2007). Por conseguinte, nesse contexto, os modelos assistenciais começaram a ser debatidos na ótica dos determinantes sociais da saúde (DSS), e a proposta da VS foi entendida como a mais condizente para o enfrentamento dos problemas e agravos que comprometem a qualidade de vida da população. As ações de vigilância, promoção da saúde e prevenção/controle de doenças e agravos foram incorporadas para transformar o modelo de atenção (Brasil, 2009b; Fortes, Oliveira e Ferreira, 2009).

As docentes D9 e D10 destacaram a PS nas ações propostas aos alunos, e D2 mencionou aspectos relacionados à reorganização dos serviços, considerando a oferta de ações dirigidas ao atendimento da chamada demanda espontânea e a grupos populacionais específicos, assim como a proposta da VS como modelo de superação dessa forma de atenção. Entretanto, apesar da clareza conceitual da D2, as ações propostas aos estudantes estavam alicerçadas no modelo assistencial vigente (na oferta organizada de serviços).

A gente trabalha com esse modelo ainda de porta aberta (...) ou demanda agendada para aqueles grupos prioritários (...). A gente até tentou (...) fazer trabalho de Vigilância em Saúde, esse novo modelo de assistência, mas não 'vingou' (D2).

Com o depoimento de D2, faz-se necessário conceituar o modelo assistencial, que "é a forma como se organizam os diferentes serviços de saúde e, principalmente, a lógica que embasa essa organização" (Brasil, 2002, p. 21); e VS, compreendida como um processo abrangente e complexo visando ao enfrentamento dos muitos problemas e agravos que comprometem a qualidade de vida das populações. A VS constitui o modelo assistencial capaz de adequar as ações e os serviços de saúde à realidade da população e de organizar práticas de saúde que garantam a PS, a integralidade da atenção e a responsabilização pela saúde da população. Constitui, também, uma proposta de redefinição das práticas sanitárias em uma dimensão técnica - expressa pelo conjunto de tecnologias distintas cujo destino é controlar determinantes, riscos e danos à saúde - e uma dimensão gerencial - organização dos processos de trabalho em saúde com o objetivo de enfrentar as problemáticas cotidianas e os DSSs, em um território delimitado, com ações planejadas pela equipe de saúde local e a população (Fortes, Oliveira e Ferreira, 2009).

Como já visto nas DCNs, a formação em saúde tem de sensibilizar o aluno para lidar com os problemas que afetam a saúde das populações, com conhecimentos e técnicas advindos da epidemiologia, da SC, das ciências da saúde, sociais e específicas a cada profissão, no intuito de acompanhar, controlar e resolver os problemas de saúde das populações (Brasil, 2001). O desenvolvimento desse compromisso com a resolução de tais problemas prevê uma prática pedagógica com ações voltadas à promoção da qualidade de vida em uma lógica organizacional condizente. 


\section{O plano de ação docente}

As temáticas relacionadas ao processo de seleção e organização dos conteúdos não traduzem os conhecimentos essenciais para o curso de graduação em enfermagem, que contemplam as ciências biológicas e da saúde, as ciências humanas e sociais e as ciências da enfermagem (fundamentos, assistência, administração e ensino de enfermagem) atreladas ao entendimento do processo saúde-doença considerando os DSSs (Brasil, 2001). Ao considerarem as ciências da enfermagem, as docentes organizam os conteúdos sob a égide da assistência de enfermagem. Os conteúdos teóricos e práticos que compõem a assistência de enfermagem são focados no indivíduo (e não no indivíduo e na coletividade), em uma fase da vida (e não em todo o ciclo vital); desconsideram a determinação do processo saúde-doença e as necessidades de compreensão pelo aluno de todas as dimensões do sistema de saúde, dos processos de gestão e das ações de controle social (Brasil, 2004).

Outro aspecto importante na elaboração do plano de ação pelos docentes participantes desta pesquisa referiu-se ao conceito de competência, que se encontra distante do conceito recomendado pelo Ministério da Saúde em suas publicações. O Ministério da Saúde estabelece em suas bases teórico-conceituais e metodológicas a noção de competência como instrumento de cidadania, adaptada às necessidades sociais da população, e não do processo produtivo, a fim de superar a visão tecnicista e estimular a produção de pensamento e da integralidade (Marques e Egry, 2011; Carvalho e Ceccim, 2007).

Os depoimentos e a literatura a seguir ilustram o contexto supracitado.

Desenvolvo tudo: Papanicolau, sala de vacina (...) HGT (...). Eu uso a rotina (...) a demanda (D1).

Oriento, ensino técnicas e tudo mais (...) cuidados com o recém-nascido, fala de algumas patologias, bem simples e básicas (D3).

Therrien, Mamede e Loiola (2004) enfatizam que os docentes são mediadores entre os conhecimentos científicos e os alunos, podendo adaptar os conteúdos de ensino, a organização e a estrutura dos conhecimentos. Somente duas docentes relataram selecionar e organizar os conteúdos, fundamentadas no currículo da IES à qual pertencem. Uma das docentes avançou na discussão, articulando os conteúdos programáticos aos planos de ação curricular. Entretanto, os conteúdos estavam atrelados a procedimentos. O depoimento de D7 elucidou a situação:

A universidade fez uma reestruturação curricular para a área comunitária e não mais para o tratamento do paciente doente (...) nós seguimos aquilo, que é o mínimo 
necessário (...). Toda pessoa com quarenta anos ou mais (...) tem que verificar pressão arterial, fazer teste de glicemia capilar, relação cintura/quadril (...) orientação para o planejamento familiar, para o método de proteção (...) imunização (D7).

O plano de ação curricular também sofria influências das perspectivas de cada tendência. Para Lopes (2000, p. 13), se o plano de ação curricular priorizar "o que fazer e como fazer" e não "por que fazer e para que fazer", está alicerçado em aspectos técnicos.

A fala de Dll ilustra a influência da perspectiva liberal e nos leva a pensar sobre as forças ou influências que determinam o seu planejamento, sua função didática e pedagógica e a sua real autonomia:

A seleção e organização dos conteúdos são enviadas pela coordenação geral, mas realizamos a avaliação destes processos e verificamos se está com a nossa realidade, então realizamos um plano esquematizando tudo o que iremos realizar durante aquele semestre (D11).

A afirmação da docente poderia nos levar a inferir um quadro de formação eminentemente tecnicista, no qual existe um controle central sobre a ação dos professores. Há a fragmentação da prática educativa: de um lado, o grupo que planeja, e de outro, os que executam. Para Sacristán (2000), essa abordagem pode levar ao individualismo profissional, que por sua vez leva à restrição do papel do docente,

pois resulta em uma abordagem cerceadora de aspectos educativos que requerem uma atuação coletiva coordenada. O planejamento ou a programação do currículo em equipe é exigência da necessidade de oferecer aos alunos um projeto pedagógico coerente e, nessa medida, pede-se uma instância modeladora do currículo no nível supraindividual. Ou seja, os processos de mediação dos professores entre o currículo prescrito ou o que a eles se apresenta e a prática real com os alunos são processos que se produzem no grupo e nos indivíduos (...) (Sacristán, 2000, p. 196).

As atividades rotineiras, planejadas ou não, desenvolvidas no espaço educativo, caracterizam a prática pedagógica docente. Entretanto, só produzem transformações sociais se planejadas (Souza, 2005), a fim de garantir intervenções na realidade. Todavia, na fala de algumas docentes verificou-se que essas vivências estavam ao acaso da demanda, da rotina dos serviços, dos procedimentos. Sem a demanda, não é possível a vivência.

O que eu planejo para eles é que acompanhem consultas de enfermagem de pré-natal. Se for possível, que eles vejam as outras coisas. Eles veem, mas nem todo mundo (D8). 
Às vezes é difícil porque não aparecem determinadas situações (...) já não tem curativo, não tem inalação, não tem vacina, não tem mais consulta médica, então o que você fica fazendo com o aluno lá? (D1).

Para Bordenave e Pereira (2002), um erro de definição muitas vezes prejudica a prática pedagógica docente no quesito das vivências, pois esses autores acreditam que o planejamento só se aplica a aulas teóricas e não a práticas. É tarefa do docente a seleção dos conteúdos e métodos mais relevantes para a ação educativa, considerando o contexto educacional e os planos curriculares oficiais, entre outros aspectos, como os culturais e as características do alunado. Independentemente dos aspectos conjunturais e estruturais que se refletem na seleção de conteúdos e nas estratégias didáticas, o docente precisa ter em mente os motivos pelos quais selecionou alguns conteúdos e excluiu outros; traçou determinados objetivos e não outros; quais comportamentos são desejáveis à formação do indivíduo e do grupo na construção da identidade profissional e como desenvolver o processo de avaliação (Lopes, 2000).

Na seleção das atividades de ensino, existem problemas relativos à formação pedagógica, tais como: a carência de critérios que orientem a escolha dos métodos (as bases; materiais que a escola fornece; as características do alunado em articulação com os objetivos e a estrutura do assunto a ser ensinado); o repertório didático alicerçado em um número bastante reduzido de técnicas de ensino; o desconhecimento das possibilidades e dos limites das técnicas; e o tempo reduzido para o desenvolvimento das atividades decorrentes de currículos sobrecarregados que não permitem a utilização de atividades de ensino variadas (Bordenave e Pereira, 2002).

Em relação à seleção das atividades de ensino, o docente tem de considerar também que os modos de ensinar e os modos de aprender são aspectos centrais do método. Cada aluno tem um modo de aprender que é pessoal e particular. Carbonell (2002) salienta:

Um maior conhecimento sobre como funciona a aprendizagem é imprescindível para averiguar os níveis reais de compreensão dos alunos em relação a diversas atividades e aquisições nas diferentes fases da aprendizagem (Carbonell, 2002, p. 72).

Ou seja, os docentes precisam se apropriar das teorias de aprendizagem para compreender a indissociabilidade entre conteúdos e métodos no processo de ensino-aprendizagem.

$\mathrm{O}$ autor relata que, na pedagogia tradicional, a aula magistral (expositiva) é o método mais utilizado, e o esquema de exposição-escuta-memorização-repetição é o mecanismo de ensino-aprendizagem de predileção. O método 
não é valorizado, pois a execução do programa é o centro da ação, e não o aluno. Na pedagogia crítica ou inovadora, o método é adaptável à realidade social e educativa da escola. Os docentes vão articulando métodos e conteúdos para o desenvolvimento do pensamento crítico e reflexivo e para atender às necessidades dos alunos por meio de práticas metodológicas que estimulam a colaboração, a cooperação, o trabalho de campo, a investigação do meio, a investigação-ação, o método científico, o construtivismo, os enfoques globalizados, o diálogo, a formulação e resolução de problemas relevantes, os grupos de discussão e reflexão, as narrativas de histórias cativantes e a avaliação contínua.

Somente uma docente desta pesquisa expressou o uso de tecnologias como recurso metodológico no ensino:

Aquelas aulas lineares, verticalizadas não adiantam mais (...). Eu uso todas as ferramentas deles [alunos]: facebook (...) eu envio texto, eles me mandam o texto discutido, e aí a gente faz uma roda de conversa pra discutir o texto (D5).

A fala da docente, no aspecto da construção coletiva do conhecimento, por meio do diálogo e da troca de experiências e saberes, nos remete à LDB, $\operatorname{artigo~} 1^{\circ}$, na abrangência do conceito de educação que envolve os processos formativos desenvolvidos na convivência humana, nas práticas sociais, nas instituições de ensino e pesquisa, entre outros. O ensino deve ser ministrado em princípios fundamentados no indivíduo e em sua vida na sociedade (Meneses et al., 2004). Assim, não basta selecionar apenas conteúdos técnico-científicos, mas é necessário que ocorra a produção de subjetividade, de habilidades técnicas, de pensamento e concepções e valores sobre o SUS (Brasil, 2004). Nesse sentido, as DCNs apontam a resolução de situações-problema como uma das estratégias didáticas necessárias para o alcance dessas produções (Brasil, 2001). Entretanto, a fala da grande maioria das docentes aproximou-se da pedagogia tradicional, prevalecendo a transmissão do conteúdo das ciências biológicas e da saúde por meio da exposição oral e a reprodução de técnicas biomédicas em detrimento dos princípios mais marcantes da SC. O fragmento ilustra:

Durante o dia a dia (...) um caso de um colo com uma ectopia: então, o que é ectopia, o que é metaplasia (...). Então, a gente conversa demais depois da prática sobre tudo isso (D3).

Ceccim e Bilibio (2004, p. 9) verbalizam que estudos sobre o SUS e a SC não têm o prestígio necessário na organização curricular dos cursos de graduação na área da saúde, apresentando-se muitas vezes como um dado isolado e não uma produção: “A concepção hospitalocêntrica, medicocentrada 
e procedimento-centrada (medicalizadora) da saúde ocupa um espaço hierarquicamente superior na cultura acadêmica ou na imagem do trabalho em saúde."

Ao se analisarem os depoimentos das docentes, notou-se a desarticulação teórica de conteúdos relacionados ao SUS na organização curricular dos cursos, traduzida pela seleção de atividades de ensino de cunho individual e assistencial na construção da identidade profissional.

Partia da realidade do aluno. Então, o que você fez hoje que você poderia notificar como uma coisa diferente? "Ah, eu fiz uma visita domiciliar de um recém-nascido de baixo, de alto risco, que acabou de chegar." (...) Nós construímos um cuidado (...). Eu procurei sempre desenvolver essa habilidade a partir da realidade dele. Então a (...) teoria iluminando aquela prática (D5).

De acordo com as narrativas, a identidade profissional mais bem traduzida em imagem do enfermeiro no trabalho em saúde, bastante alicerçada no senso comum, foi demonstrada somente por duas das docentes. O depoimento de D3 ilustra:

(...) Que tenha certa liderança (...) porque o profissional da SC ele não pode ser tão autoritário e nem ser tão liberal (...) gostar da prevenção (...) principalmente, das pessoas da classe social mais baixa e que consiga trabalhar com essas pessoas (D3).

Na narrativa docente, as atividades de integração entre os princípios e diretrizes do SUS e a prática clínica, assim como o desenvolvimento da reflexão crítica e da atitude contestatória, se afastavam de uma organização que possibilitasse uma abordagem reflexiva na construção educativa.

Eu uso a rotina (...) deixo um ou dois alunos na farmácia (...) então eles veem a situação epidemiológica (...) ações que vão acontecendo, a demanda (D1).

D5 avançou um pouco mais, demonstrando maior articulação entre teoria e prática e clareza sobre o planejamento do estágio.

(...) enquanto princípios e diretrizes do SUS, eu dou todo um aporte teórico primeiro (...). Então daí ele vai ver universalidade: (...) olha, parou aquele carrão e veio pegar uma receita, nem é do SUS, mas veio pegar (...) maior dificuldade é a equidade (...). Então você dá mais a quem mais precisa, e fazer toda uma estratégia, uma planificação dos seus cuidados com este olhar, é difícil. Até a própria unidade também não faz, então o aluno também tem dificuldade de ver a equidade funcionando (...) muitas vezes, o estágio está em cima da demanda (D5). 
D4 e D6 fizeram considerações sobre o exercício de análise da realidade em uma perspectiva muito reduzida de reflexão e da relação professor-aluno.

Ele [aluno] não tem uma postura ética. Então você tem que trabalhar isso. Olha, você não viu nada de bom aqui dentro? Como é seu conhecimento? Como é a sua técnica de curativo? Eu também tenho direito de te falar. Você não fez nada certo. Você entrou criticando tudo, e o que você fez tá errado! (D4).

(...) é a crítica pela crítica, ele não consegue fazer uma análise (...) ele critica o profissional, ele critica a atitude, mas ele não faz uma reflexão por que é que tá desse jeito. Aí a gente tem meio que direcionar (D6).

Aqui entra um aspecto fundamental da construção da identidade profissional quanto às posturas em relação aos futuros colegas profissionais e aos usuários dos serviços de saúde. Se a formação acontecer de modo precário, acrítico, fragmentado (que leva a práticas inadequadas), como construir uma visão de compromisso ético? Para o enfermeiro, valem as reflexões de Faraco e Jaeger (2010) sobre a ética na intervenção social:

A Ética na Intervenção Social é uma ética social, prática e realizável que pode orientar de forma eficaz o comportamento ético do interventor frente a circunstâncias diversas como: identificação de metas e objetivos e resolução de problemas e conflitos. É uma ética tanto mais necessária, quanto mais desregulado for o contexto social da intervenção. É uma ética construída a partir de valores socialmente relevantes e com consequências das ações que diferem significativamente da ética individual (Faraco e Jaeger, 2010, p. 215-216).

O docente tem a função de auxiliar o crescimento do aluno como ser humano e cidadão. De volta à literatura, é importante salientar que: o professor é quem viabiliza as práticas e as atitudes construtivas e reflexivas dos alunos; e os objetivos da formação fundamentam-se na transformação das práticas profissionais e da organização dos processos de trabalho a partir da problematização (Brasil, 2004).

Para Pimenta e Lima (2008), o estágio supervisionado deve possibilitar a interação entre o aluno, o docente orientador do estágio e os profissionais do serviço. Todavia, conforme Campos, Pierantoni e Machado (2006), o diálogo é estreito entre o ensino e o serviço e, por muitos anos, o 'serviço' foi identificado como local de 'má prática', inadequado para o processo de formação de um bom profissional. Essas situações, segundo os autores, auxiliam a perpetuação da alienação dos graduandos da área da saúde em relação à realidade social, aos conflitos de interesse entre o sistema de saúde e o aparelho formador. 
As narrativas docentes expressaram a desarticulação entre o serviço e o ensino. Quando as docentes afirmavam haver uma articulação, ficaram explícitas duas situações: a simpatia pessoal da enfermeira que permitia o desenvolvimento das atividades educativas; e a adesão da academia a programas de reorientação profissional por meio de parceria com a Secretaria Municipal da Saúde. No caso da pesquisa, os depoimentos de D5 e D1 ilustram a primeira situação, e a narrativa de D8, a segunda, em que referenciaram o Programa de Educação pelo Trabalho para a Saúde (PET-Saúde).

Ficou com o aluno o tempo todo (...). Agora tem lugares onde a enfermeira do campo deixa o aluno bem mais solto mesmo (D5).

Eu tenho apoio (...) A enfermeira chama (...) "eu vou fazer uma notificação de trichomonas: dá um aluno que vai me acompanhar" (...) olha, tem um curso tal... chegou um novo (D1).

Atualmente, não tem nenhum profissional de nível superior da Secretaria Municipal de Saúde que não receba uma bolsa de estudos do Programa de Educação pelo Trabalho para a Saúde (PET) (...) faz parte da função do bolsista receber e orientar os alunos de graduação (D8).

A integração ensino-serviço tem como marcos projetos e programas de incentivo às transformações do processo de formação para uma abordagem integral do processo saúde-doença, tais como: a Integração Docente Assistencial (IDA), em 1983; o Projeto UNI (1990); o Programa de Incentivo às Mudanças Curriculares (Promed), em 2002; o Programa Nacional de Reorientação da Formação Profissional em Saúde (Pró-Saúde), em 2005. Na educação superior, destacam-se também: a Residência Multiprofissional em Saúde, a Universidade Aberta do Sistema Único de Saúde (UNA-SUS) e o Programa de Educação pelo Trabalho para a Saúde (PET-Saúde), instituído pela portaria interministerial MS/MEC n. 1.802/2008. Este, por sua vez, constitui-se como uma das estratégias do Pró-Saúde (Brasil, 2009b). O fio condutor do PET é a integração ensino-serviço-comunidade, uma parceria entre a Secretaria de Gestão do Trabalho e da Educação da Saúde (SGTES) e a Secretaria de Atenção à Saúde, do Ministério da Saúde, e da Secretaria de Educação Superior, do Ministério da Educação (Brasil, 2008b, 2009b).

Ainda segundo Campos, Pierantoni e Machado (2006), sobre a questão de o 'serviço' ser um local de 'má prática', algumas docentes expressaram a ideia de que o 'serviço' era um espaço difícil de trabalhar devido à escassez de recursos assistenciais e da demanda não dirigida, caracterizando uma situação de prejuízo ao processo de ensino-aprendizagem (principalmente 
porque o processo estava alicerçado nas ações, nas atividades profissionais e em algumas atividades próprias da SC, como a visita domiciliária):

A unidade só vai a casa quando solicitado por alguém da família (...) dá uma avaliada, faz algumas orientações e vai embora (...) a unidade está com um número muito reduzido de auxiliar de enfermagem (D4).

Não há trabalho em grupo (...) de hipertenso, de diabético (...) não tem nada (...) a gente se engaja naquilo que a unidade oferece (D2).

Em relação à alienação, destacada também pelos autores citados, as narrativas de D4 e D5 expuseram sutilmente a situação:

(...) aluno que ele só quer pegar o papel (...) pra ir embora ele só quer o diploma (D4).

Esse aluno, ele tem vindo mais fraco, mais desestimulado, e com menos paixão pela enfermagem do que no meu tempo. (D5).

Para Pimenta e Anastasiou (2010), os professores formadores desses alunos não têm em mente o aluno real, decepcionando-se, muitas vezes, com os comportamentos e as intenções deles. A mudança desse quadro passa pela superação do individualismo profissional que, ainda de acordo com as autoras, se dá na medida em que os professores

institucionalmente organizados procedem ao conhecimento e à identificação de quem são esses alunos, o que pensam, o que sabem, suas expectativas, a visão que têm do que é ser profissional da área 'escolhida' (Pimenta e Anastasiou, 2010, p. 229).

Ao se aprofundar um pouco a análise, na tentativa de finalizar, Ferreira e Ramos (2006) destacam que os contextos e conflitos das vivências e convivências coletivas e profissionais são importantes como opção a métodos e estratégias de ensino de transmissão de normas e valores aos alunos. Com dados da realidade, professor e alunos dialogam, e a relação ensino-aprendizagem se dá de maneira mais eficaz. Para Luckesi (1996), a educação reproduz o vigente na sociedade, mas também a renova, e o desenvolvimento do educando deve contemplar diversas peculiaridades próprias do ser humano, levando-o à formação de crenças afetivas, políticas e sociais. O autor alerta sobre qual cidadão se quer formar.

Para que o aluno, como egresso/formando, seja capaz de transformar as práticas profissionais e a organização do trabalho com base na problematização do processo de trabalho, ele tem de compreender os conflitos de 
interesses e os ditames da política de mercado sobre o sistema de saúde e principalmente sobre os interesses do usuário.

\section{Considerações finais}

Os depoimentos das docentes propiciaram um material relevante para as questões referentes à prática pedagógica, à educação na área da saúde e à formação para o SUS. Em virtude das características de uma investigação em nível de mestrado, as considerações acerca do objeto do estudo e da problemática do trabalho foram restritas, mas permitiram concluir que o contexto da formação ainda é de transição de paradigmas conceituais e práticos, tanto no campo da educação quanto no da saúde. No campo da saúde, compreende-se essa transição pelas contradições entre o paradigma dominante (biológico) e o paradigma da construção social da saúde.

Ao se destacarem as discussões sobre o trabalho docente no quesito formação e história de formação, concluiu-se com a pesquisa que a ausência da licenciatura nos cursos em que as docentes estavam inseridas pode restringir ainda mais as representações do docente acerca da educação e dos processos de ensino-aprendizagem, pois o saber pedagógico fica restrito a reflexões coletivas do corpo docente sobre 'o fazer', afastando-se do que é fundamental na graduação (e na graduação na área da saúde): o desenvolvimento do pensamento crítico, do aprender a aprender, do diálogo e da capacidade de transformar a realidade social.

A formação em cursos de mestrado e doutorado no Brasil não garante a assimilação de concepções teóricas rigorosas nem a articulação entre processos de ensino e planejamento da ação, condizentes com um referencial teórico-metodológico na área da educação. A configuração da pós-graduação stricto sensu não permite o desenvolvimento da licenciatura.

Em relação aos referenciais da SC, estes deveriam estar presentes no planejamento da ação. A grande maioria das docentes tinha pós-graduação stricto sensu - mestrado nesta área; entretanto, os princípios mais marcantes da SC não foram identificados nas narrativas.

A formação acadêmica das entrevistadas foi auxiliada por docentes formados em uma fase anterior ao SUS, com todas as características da educação liberal, da verticalização do conhecimento, do modelo assistencial médico-privatista, da assistência individual. Assim, é possível que o docente reproduza no seu processo de trabalho o que vivenciou na sua formação, comprometendo o entendimento da ação pedagógica como parte de um processo social e de um exercício social maior.

A prática pedagógica dos docentes entrevistados sofre influência da cultura institucional da educação superior brasileira, voltada para as profis- 
sões. As atividades rotineiras, desenvolvidas no estágio curricular em SC, estão calcadas em: conteúdos das ciências biológicas e da saúde organizados sob a égide da assistência de enfermagem, em detrimento dos fundamentos, da pesquisa e da administração em enfermagem; exposição oral e reprodução de técnicas biomédicas; desarticulação entre teoria e prática; e isolamento do trabalho docente, sem apoio/parceria dos serviços de saúde no desenvolvimento das atividades educativas. Essas atividades, em que os procedimentos técnicos mostram-se supervalorizados, são desenvolvidas dentro dos serviços de saúde, sem participação ativa da comunidade, sem ações de cunho coletivo - enfim, distante de uma formação generalista e humanística que atenda às necessidades da população.

Como se pode concluir das questões anteriormente abordadas, muitos são os fatores que dificultam a produção de perfis profissionais ajustados ao SUS. O preparo e a ação pedagógica são cruciais, no sentido de que cabe ao docente propiciar experiências de aprendizado significativas e transformadoras das práticas profissionais.

Os resultados sugerem que as competências científicas, técnicas, didáticas e práticas dos docentes (ou competências educacionais, organizacionais e relacionais dos docentes) precisam ser ampliadas em direção ao planejamento da ação pedagógica, aproximando-se dos referenciais teóricos e filosóficos do SUS e da educação contemporânea, em busca de uma prática integrada, coletiva, democrática, promotora da saúde e da qualidade de vida.

\section{Colaboradores}

Patrícia Ribeiro Mattar Damiance e Maria de Lourdes da Silva Marques Ferreira trabalharam na concepção, delineamento e redação do artigo. Vera Lúcia Pamplona Tonete e Ana Maria Lombardi Daibem, na redação final e revisão crítica. José Roberto de Magalhães Bastos, na revisão crítica. Não houve financiamento e não há conflito de interesses. 
Resumen La preparación pedagógica del docente del área de la salud, frente a las exigencias de la educación contemporánea y las directrices curriculares nacionales, guarda una relación directa con la formación de profesionales para atender las necesidades del Sistema Único de Salud. Fundamentado en esa premisa, este estudio buscó analizar perfil de formación, bases de la acción y planificación pedagógica del docente de enfermería orientador de la pasantía en Salud Colectiva de instituciones de enseñanza superior de dos municipios de la región centro oeste del estado de San Pablo, Brasil, a la luz de las políticas públicas de educación y salud. Los datos obtenidos se sometieron a análisis de contenido, modalidad temática. El análisis llevado a cabo señaló que la práctica pedagógica de los 11 docentes entrevistados presentaba influencia de la cultura institucional de la educación superior brasileña. Las actividades rutinarias estaban inspiradas en contenidos de las ciencias biológicas, organizados en torno a la asistencia de enfermería; en la exposición oral y reproducción de técnicas biomédicas; en la desarticulación entre teoría y práctica y en el aislamiento del trabajo docente. Se concluyó que las competencias docentes en las dimensiones educativas, organizacionales y relacionales deben ser ampliadas en dirección a la planificación de la acción pedagógica, aproximándose a las referencias teóricas y filosóficas del SUS y de la educación contemporánea, en busca de una práctica integrada, colectiva, democrática, promotora de la salud y la calidad de vida.

Palabras clave educación; enseñanza; Salud Colectiva; Sistema Único de Salud; residencia.

\section{Notas}

1 Universidade de São Paulo, Faculdade de Odontologia de Bauru, Departamento de Ortodontia e Saúde Coletiva, São Paulo, Brasil.

<patricia.mattar@usp.br>

Correspondência: Universidade de São Paulo, Faculdade de Odontologia de Bauru, Alameda Octávio Pinheiro Brisola, 9-75, CEP 17.012-901, Bauru, São Paulo, Brasil.

2 Universidade Estadual Paulista Júlio de Mesquita Filho, Faculdade de Medicina de Botucatu, São Paulo, Brasil.

<pamp@fmb.unesp.br>

3 Universidade Estadual Paulista Júlio de Mesquita Filho, Centro de Estudos e Práticas Pedagógicas, Bauru, São Paulo, Brasil.

$<$ amldaibem@zipmail.com>

4 Universidade Estadual Paulista Júlio de Mesquita Filho, Faculdade de Medicina de Botucatu, São Paulo, Brasil.

$<$ malusa@fmb.unesp.br>

5 Universidade de São Paulo, Faculdade de Odontologia de Bauru, Departamento de Ortodontia e Saúde Coletiva, São Paulo, Brasil.

<zeromaba@fob.usp.br> 


\section{Referências}

ALMEIDA FILHO, Naomar. Formação do profissional de saúde não atende demandas do SUS. Entrevista a Filipe Leonel. Informe Ensp, Rio de Janeiro, 27 mai. 2011. Disponível em: <www.ensp.fiocruz.br/portalensp/informe/materia/?origem $=1 \&$ matid $=$ 25644>. Acesso em: 15 jun. 2015.

BARDIN, Laurence. Análise de conteúdo. 5. ed. Lisboa: Edições 70, 2010.

BORDENAVE, Juan D.; PEREIRA, Adair M. Estratégias de ensino-aprendizagem. 24. ed. Rio de Janeiro: Vozes, 2002.

BRASIL. Constituição da República Federativa do Brasil. Brasília: Senado, 1988. Disponível em: <www.planalto.gov.br/ccivil_ 03/constituicao/constituicao.htm $>$. Acesso em: 15 jun. 2015.

BRASIL. Ministério da Saúde. Politica de Recursos Humanos em Saúde. Brasília: Secretaria de Políticas de Saúde. Coordenação Geral de Desenvolvimento de Recursos Humanos para o Sistema Único de Saúde (SPS/ CGDRH/SUS), 1999. Mimeografado.

BRASIL. Ministério da Educação. Parecer CNE/CES n. 1.133/2001. Diretrizes Curriculares Nacionais dos Cursos de Graduação em Enfermagem, Medicina e Nutrição. Diário Oficial da União, Poder Executivo, Brasília, 3 out. 2001. Seção 1E, p. 131. Disponível em: $<$ http://portal.mec.gov.br/dmdocuments/ ces1133.pdf>. Acesso em: 18 jun. 2016.

BRASIL. Ministério da Saúde. Projeto de profissionalização dos trabalhadores da área de enfermagem: profissionalização de auxiliares de enfermagem: cadernos do aluno - Saúde Coletiva. 2. ed. rev. Brasília: Ministério da Saúde, 2002.

BRASIL. Ministério da Saúde. Aprender SUS: o SUS e os cursos de graduação da área da saúde. Brasília: Ministério da Saúde, 2004.

BRASIL. Ministério da Saúde. A educação permanente entra na roda: polos de educação permanente em saúde - conceitos e caminhos a percorrer. Brasília: Ministério da Saúde, 2005.

BRASIL. Ministério da Saúde. Fundação Oswaldo Cruz. Dinâmica das graduações em saúde no Brasil: subsídios para uma política de recursos humanos. Brasília: Ministério da Saúde, 2006.

BRASIL. Ministério da Saúde. Secretaria de Vigilância à Saúde. Secretaria de Atenção à Saúde. Diretrizes e recomendações para o cuidado integral de doenças crônicas não transmissíveis: promoção da saúde, vigilância, prevenção e assistência. Brasília: Ministério da Saúde, 2008a. Disponível em: <http://bvsms. saude.gov.br/bvs/publicacoes/diretrizes_ recomendacoes_cuidado_doencas_cronicas. pdf >. Acesso em: 18 jun. 2016.

BRASIL. Ministério da Saúde. Ministério da Educação. Portaria interministerial $n$. 1.802 de 26 de agosto de 2008. Institui o Programa de Educação pelo Trabalho para a Saúde - PET-Saúde. Diário Oficial da União, Poder Executivo, Brasília-DF, 27 ago. 2008b. Seção 1, p. 27. Disponível em: <http://bvsms. saude.gov.br/bvs/saudelegis/gm/2008/ pril802_26_08_2008.html>. Acesso em: 18 jun. 2016 .

BRASIL. Ministério da Saúde. Secretaria de Gestão do Trabalho e da Educação na Saúde. Departamento de Gestão da Educação em Saúde. Política Nacional de Educação Permanente em Saúde. Brasília: Ministério da Saúde, 2009a. Disponível em: <http://bvsms.saude. gov.br/bvs/publicacoes/politica_nacional_ educacao_permanente_saude.pdf $>$. Acesso em: 18 jun. 2016.

BRASIL. Ministério da Saúde. Secretaria Executiva. Secretaria de Gestão do Trabalho e da Educação na Saúde. Glossário temático: gestão do trabalho e da educação na saúde. Brasília: Ministério da Saúde, 2009b. Disponível em: <http://bvsms.saude.gov.br/bvs/ publicacoes/glossario_sgtes.pdf $>$. Acesso em: 18 jun. 2016. 
BUSS, Paulo M. Promoção da saúde e prevenção de riscos e doenças. In: BUSS, Paulo M. SEMINÁRIO SOBRE PROMOÇÃO DA SAÚDE E PREVENÇÃO DE RISCOS E DOENÇAS NA SAÚDE SUPLEMENTAR, 4., Rio de Janeiro, 2007. Anais... Disponível em: $<$ www.determinatessociais.fiocruz.br $>$. Acesso em: 18 jun. 2016.

CAMPOS, Florianita C. B. Os desafios do matriciamento. Psi Jornal de Psicologia, São Paulo, n. 158, p. 21, jan. 2009.

CAMPOS, Francisco E.; PIERANTONI, Célia R.; MACHADO, Maria H. Introdução. Cadernos RH Saúde, Brasília, v. 3, n. 1, p. 9-12, mar. 2006. Disponível em: <http://bvsms.saude. gov.br/bvs/publicacoes/cadernos_rh.pdf > . Acesso em: 18 jun. 2016.

CARBONELL, Jaime. A aventura de inovar: a mudança na escola. Porto Alegre: Artmed, 2002.

CARVALHO, Yara M.; CECCIM, Ricardo B. Formação e educação em saúde: aprendizados com a saúde coletiva. In: CAMPOS, Gastão W. S.; MINAYO, Maria C. S.; AKERMAN, Marco; DRUMOND JÚNIOR, Marcos; CARVALHO, Yara M. (org.). Tratado de Saúde Coletiva. São Paulo: Hucitec; 2007. p. 137-70.

CATANI, Denice B.; GALLEGO, Rita. C. Avaliação. São Paulo: Editora Unesp, 2009.

CECCIM, Ricardo B.; BILIBIO, Luiz F. S. Articulação com o segmento estudantil da área da saúde: uma estratégia de inovação na formação de recursos humanos para o SUS. In: BRASIL. Ministério da Saúde. Secretaria de Gestão do Trabalho e da Educação na Saúde. Departamento de Gestão da Educação na Saúde. VER-SUS Brasil: Caderno de textos. Brasília: Ministério da Saúde, 2004. p. 8-31.

DURÃO, Anna V.; MOROSINI, Márcia Valéria; CARVALHO, Valéria. Os agentes comunitários de saúde e o conceito de comunidade na configuração de sua qualificação. In: VIEIRA, Monica; DURÃO, Anna V.; LOPES, Marcia R. (orgs.). Para além da comunidade: trabalho e qualificação dos agentes comunitários de saúde. Rio de Janeiro: EPSJV, 2011. p. 119-159. Disponível em: <www.fiocruz.br/media/livro_ epsjv.pdf>. Acesso em: 18 jun. 2016.

FARACO, Ceres. B.; JAEGER, Maria A. A ética na intervenção psicossocial. In: SARRIERA, Jorge C.; SAFORCADA, Enrique. T. (orgs.). Introdução à psicologia comunitária: bases teóricas e metodológicas. Porto Alegre: Sulina, 2010. p. 215-227.

FERREIRA, Heliane M.; RAMOS, Laís H. Diretrizes curriculares para o ensino da ética na graduação em enfermagem. Acta Paulista de Enfermagem, São Paulo, v. 19, n. 3, p. 328-331, mar. 2006.

FORTES, Júlia I.; OLIVEIRA, Solange C.; FERREIRA, Vânia C. Curso técnico de nível médio em enfermagem: módulo de habilitação guia curricular - área I - promovendo a saúde. São Paulo: Fundap, 2009.

LEAVELL, Hugh; CLARK, Gurney. Medicina preventiva. São Paulo: McGraw-Hill, 1976. $744 \mathrm{p}$.

LOBO NETO, Francisco J. et al. Educação, sociedade, cultura. In: BRASIL. Ministério da Saúde. Formação pedagógica em educação profissional na área da saúde: enfermagem. Núcleo contextual [curso]. Brasília: Ministério da Saúde, 2000. (Módulo 2). Disponível em: <http://bvsms.saude.gov.br/bvs/publicacoes/ form_ped_modulo_02.pdf $>$. Acesso em: 18 jun. 2016.

LOPES, Alice R. C. Proposta pedagógica: o plano da ação. Brasília: Ministério da Saúde, 2000.

LUCKESI, Cipriano C. Avaliação da aprendizagem escolar. 3. ed. São Paulo: Cortez, 1996.

MARQUES, Cláudia M. S.; EGRY, Emiko Y. As competências profissionais em saúde e as políticas ministeriais. Revista da Escola de Enfermagem da USP, São Paulo, v. 45, n. 1, p. 187-193, mar. 2011.

MENESES, João G. C. et al. Educação básica: políticas, legislação e gestão - leituras. São Paulo: Thomson, 2004. 
PIMENTA, Selma G.; ANASTASIOU, Léa G. Docência no ensino superior. 4. ed. São Paulo: Cortez, 2010.

PIMENTA, Selma G.; LIMA, Maria S. L. Estágio e docência. 3. ed. São Paulo: Cortez, 2008.

RODRIGUES, Malvina T. P. Os obstáculos didáticos no cotidiano da prática pedagógica do enfermeiro professor: da identificação à superação. 145fls. Dissertação (Mestrado em Educação) - Universidade Federal do Piauí, Teresina, 2008. Disponível em: <http://leg. ufpi.br/subsiteFiles/ppged/arquivos/files/ dissertacao/2008/obstaculos_didaticos.pdf > . Acesso em: 18 jun. 2016.

ROSEMBERG, Dulcinéia S. O. Processo de formação continuada de professores: do instituído ao instituinte. Niterói: Intertexto, 2002.

SACRISTÁN, José G. O currículo. 3. ed. Porto Alegre: Artmed, 2000.
SOUZA, Maria A. Prática pedagógica: conceito, características e inquietações. In: ENCONTRO IBERO-AMERICANO DE COLETIVOS ESCOLARES E REDES DE PROFESSORES QUE FAZEM INVESTIGAÇÃO NA SUA ESCOLA, 4., 2005, Lajeado, RS. Conclusões do Encontro. Lajeado, RS, Unidade Integrada Vale do Taquari de Ensino Superior (Univates), 2005. Disponível em: <http://ensino. univates.br/ 4iberoamericano/trabalhos/ trabalho024.pdf>. Acesso em: 18 jun. 2016.

THERRIEN, Jacques; MAMEDE, Maíra A.; LOIOLA, Francisco A. Gestão moral da matéria e autonomia no trabalho docente. In: ROMANOWSKI, Joana P.; MARTINS, Púra L. O.; JUNQUEIRA, Sérgio R. A. (org.). Conhecimento local e conhecimento universal: a aula, aulas nas ciências naturais e exatas, aulas nas letras e artes. Curitiba: Champagnat, 2004. v. 3. p. 43-56.

Recebido em 15/06/2014

Aprovado em 14/06/2015 